\title{
BMJ Open Hyperuricemia is independently associated with endothelial dysfunction in postmenopausal women but not in premenopausal women
}

Tatsuya Maruhashi, ${ }_{1}^{1}$ Ayumu Nakashima, ${ }^{2}$ Junko Soga, ${ }^{1}$ Noritaka Fujimura, ${ }^{1}$ Naomi Idei, ${ }^{1}$ Shinsuke Mikami, ${ }^{1}$ Yumiko Iwamoto, ${ }^{1}$ Masato Kajikawa, ${ }^{1}$ Takeshi Matsumoto, ${ }^{1}$ Takayuki Hidaka, ${ }^{1}$ Yasuki Kihara, ${ }^{1}$ Kazuaki Chayama, ${ }^{3}$ Chikara Goto, ${ }^{4}$ Kensuke Noma, ${ }^{5}$ Hirofumi Tomiyama, ${ }^{6}$ Bonpei Takase, ${ }^{7}$ Akira Yamashina, ${ }^{6}$ Yukihito Higashi ${ }^{2,5}$

To cite: Maruhashi T, Nakashima A, Soga J, et al. Hyperuricemia is independently associated with endothelial dysfunction in postmenopausal women but not in premenopausal women. BMJ Open 2013;3: e003659. doi:10.1136/ bmjopen-2013-003659

- Prepublication history and additional material for this paper is available online. To view these files please visit the journal online (http://dx.doi.org/10.1136/ bmjopen-2013-003659).

Received 25 July 2013 Accepted 2 October 2013

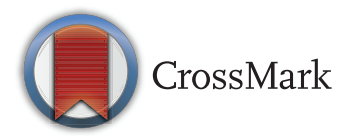

For numbered affiliations see end of article

Correspondence to Professor Yukihito Higashi; yhigashi@hiroshima-u.ac.jp

\section{ABSTRACT}

Objectives: The purpose of this study was to determine the relationships between uric acid, endothelial function and cardiovascular risk factors and to investigate whether menopausal status was associated with the relationship between uric acid and endothelial function in women.

Design: Cross-sectional study.

Setting: 3 general hospitals in Japan.

Participants: 749 Japanese women aged 30-74 years recruited from people who underwent health-screening examinations with agreement for measurement of vascular function.

Measures: We measured serum concentrations of uric acid and flow-mediated vasodilation (FMD). Percentage of FMD ( peak diameter-baseline diameter/baseline diameter) was used for analysis. Endothelial dysfunction was defined as $\mathrm{FMD} \leq 4.90 \%$, division point for the lowest tertile and the middle tertile of FMD. Menopause women were defined as participants without menstruation for over 1 year or participants with a history of hysterectomy or bilateral oophorectomy.

Results: Of the 749 participants, 368 (49.1\%) were premenopausal women and $381(50.9 \%)$ were postmenopausal women. Age, body mass index, systolic blood pressure, total cholesterol, triglycerides, glucose, estimated glomerular filtration rate and Framingham risk score were significantly correlated with serum uric acid level. FMD showed a gradual decrease in accordance with the serum uric acid level in the entire study population ( $<4 \mathrm{mg} / \mathrm{dL}, 6.85 \pm 3.65 \%$; 4 to $<5 \mathrm{mg} / \mathrm{dL}, 6.79 \pm 3.60 \%$; 5 to $<6 \mathrm{mg} / \mathrm{dL}, 6.24 \pm 3.58 \% ; \geq 6 \mathrm{mg} / \mathrm{dL}, 5.27 \pm 3.18 \%$; $\mathrm{p}=0.01$ ). Multivariate analysis revealed that uric acid was a significantly independent risk factor for endothelial dysfunction in postmenopausal women (OR 1.23, 95\% $\mathrm{Cl} 1.01$ to 1.50), but not in premenopausal women.

Conclusions: These findings suggest that uric acid can be used as a risk marker of endothelial dysfunction in a female population, and particularly as an independent risk factor in postmenopausal women but not in premenopausal women.

Registration number of the study: UMIN000003409.

\section{Strengths and limitations of this study}

- This study includes a large number of women who underwent a flow-mediated vasodilation test.

- This study shows a difference in the relationship between uric acid and endothelial dysfunction depending on menopausal status in women.

- Residual confounding may exist for this crosssectional study.

Menopausal status was based on a self-report.

\section{INTRODUCTION}

Several epidemiological studies have shown a relationship between the serum uric acid level and subsequent cardiovascular disease. ${ }^{1-10}$ In addition, an increase in the uric acid level is regarded as an independent marker of increased cardiovascular risk. However, it has remained controversial whether uric acid per se should be considered as a cardiovascular risk factor because of the difficulty in investigating the role of uric acid alone in the pathogenesis, development and maintenance of atherosclerosis. There are significant relationships between elevated uric acid levels and established cardiovascular risk factors, such as hypertension, ${ }^{11}$ metabolic syndrome ${ }^{12}$ and kidney disease, ${ }^{13}$ all of which are also well known as strong predictors of cardiovascular disease. $^{14} 15$ Some investigators have argued that elevated uric acid is not an independent risk factor but rather merely a marker of risk for cardiovascular disease. ${ }^{1} \quad 6 \quad 7$ However, recent epidemiological studies have demonstrated that uric acid is an independent risk factor for cardiovascular disease. ${ }^{5} \quad 7-10$ Although the mechanism by which uric acid causes cardiovascular disease is not fully 
understood, several lines of evidence suggest that elevated uric acid impairs endothelial function by inducing intracellular oxidative stress and inflammation through activation of the local renin-angiotensin system, particularly angiontensin II, and the pro-oxidant effect of uric acid per se, once absorbed into endothelial cells. ${ }^{16-18}$

Endothelial dysfunction is established in the initial step of atherosclerosis and plays an important role in the development of atherosclerotic conditions, leading to cardiovascular outcomes. ${ }^{19}$ Recently, the measurement of flow-mediated vasodilation (FMD) as an index of endothelium-dependent vasodilation has been widely used as a method for assessing endothelial function. ${ }^{20-24}$ In addition, growing evidence has shown that endothelial function assessed by FMD can serve as an independent predictor of cardiovascular events. ${ }^{25-28}$ Recently, several investigators, including us, have shown a relationship between uric acid and endothelial function as assessed by FMD. ${ }^{29-34}$ As for the relationship between uric acid and FMD in men, previous studies are consistent in demonstrating that uric acid is a significantly independent risk factor for FMD. ${ }^{29}{ }^{34}$ However, there is little information on whether uric acid is an independent risk factor for endothelial dysfunction in women. In addition, it remains unclear whether menopausal status is associated with the relationship between uric acid and endothelial function. It is clinically important to confirm the role of uric acid per se in atherosclerosis. We therefore investigated the relationships between uric acid, FMD and cardiovascular risk factors to see whether menopausal status was associated with the relationship between uric acid and endothelial function in women who underwent health-screening examinations.

\section{METHODS}

\section{Subjects}

A total of 5321 Japanese adults aged 17-86 years who underwent health-screening examinations with agreement for measurement of vascular function were enrolled in the Flow-mediated Dilation Japan Registry between 1 April 2010 and 31 August 2012 at three general hospitals in Japan. All employees have an obligation to undergo health screening every year under the regulations of the Society-managed Health Insurance Union in Japan. In accordance with the regulations, we performed healthscreening examinations. From the registry, 895 women aged 30-74 years were recruited for this study. Among the 895 participants, information on the serum uric acid levels, menopause and phases of menstrual cycle was available for 797 participants. Participants during menstruation $(n=28)$, participants receiving hormone replacement therapy $(n=3)$, one participant who was pregnant, participants who had been previously diagnosed with cardiovascular diseases $(n=15)$ and one participant who was being treated with an antihyperuricemic drug were excluded. Finally, 749 women without cardiovascular diseases were enrolled in this study. Hypertension was defined as systolic blood pressure of $\geq 140 \mathrm{~mm} \mathrm{Hg}$ or diastolic blood pressure $\geq 90 \mathrm{~mm} \mathrm{Hg}$, in a sitting position, on at least three different occasions. ${ }^{35}$ Patients with secondary forms of hypertension were excluded in all patients with hypertension on the basis of complete history; physical examination; radiological and ultrasound examinations; urinalysis; plasma renin activity; plasma aldosterone and norepinephrine concentrations; serum creatinine, potassium, calcium and free thyroxine concentrations; and $24 \mathrm{~h}$ urinary excretion of 17-hydroxycorticosteroids, 17-ketogenic steroids and vanillymandelic acid. Diabetes was defined according to the American Diabetes Association recommendations. ${ }^{36}$ Dyslipidemia was defined according to the third report of the National Cholesterol Education Programme (NCEP) Expert Panel on Detection, Evaluation and Treatment of High Blood Cholesterol in Adults (ATP-III). ${ }^{37}$ We defined smokers as those who were current smokers. Measurement of FMD was performed without withholding medications. Framingham risk score was calculated by points of risk factors: age, total cholesterol level, high-density lipoprotein cholesterol level, systolic blood pressure and smoking status. ${ }^{38}$ Diagnosis of metabolic syndrome was made according to the criteria of NCEP ATP-III. ${ }^{37}$ Thus, metabolic syndrome was diagnosed when three or more of the following risk determinants were present (1) waist circumference of $\geq 88 \mathrm{~cm}$, (2) triglyceride $\geq 1.7 \mathrm{mmol} / \mathrm{L}$ $(150 \mathrm{mg} / \mathrm{dL})$, (3) high-density lipoprotein cholesterol $<1.29 \mathrm{mmol} / \mathrm{L} \quad(50 \mathrm{mg} / \mathrm{dL}$ ), (4) blood pressure $\geq 130$ and/or $85 \mathrm{~mm} \mathrm{Hg}$ or (5) fasting blood glucose $\geq 6.11 \mathrm{mmol} / \mathrm{L}(110 \mathrm{mg} / \mathrm{dL})$. The estimated glomerular filtration rate (eGFR) was calculated using the Japanese eGER equation. ${ }^{39}$ Chronic kidney disease (CKD) was defined as eGFR $<60 \mathrm{~mL} / \mathrm{min} / 1.73 \mathrm{~m}^{2}{ }^{40}$ Menopause women were defined as participants without menstruation for over 1 year or participants with a history of hysterectomy or bilateral oophorectomy. ${ }^{41}$ The ethical committees of our institutions approved the study protocol. Written informed consent for participation in the study was obtained from all participants.

\section{Study protocol}

We measured vascular responses to reactive hyperaemia in the brachial artery in all participants. Participants fasted the previous night for at least $12 \mathrm{~h}$. The study began at 8:30. The participants were kept in a supine position in a quiet, dark, air-conditioned room (constant temperature $22-25^{\circ} \mathrm{C}$ ) throughout the study. After remaining in the supine position for $30 \mathrm{~min}$, blood samples were obtained for measurement of basal fasting serum concentrations of total cholesterol, triglycerides, high-density lipoprotein cholesterol, low-density lipoprotein cholesterol, creatinine, glucose and uric acid. Then FMD was measured. The observers were blind to the form of examination. Serum uric acid levels were measured by the uricase-peroxidase method (JCA-BM6010; JEOL Ltd, Tokyo, Japan). Levels of serum total cholesterol, triglycerides, high-density lipoprotein cholesterol, low-density lipoprotein cholesterol and creatinine were 
enzymatically measured (JCA-BM6010). Glucose levels were measured by the glucose oxidase immobilised oxygen electrode method (GA08II; A\&T, Yokohama, Japan).

\section{Measurement of FMD}

The participants remained supine throughout the study. The vascular response to reactive hyperaemia in the brachial artery was used for assessment of endothelium-dependent FMD. A high-resolution linear artery transducer was coupled to computer-assisted analysis software (UNEXEF18G, UNEX Co, Nagoya, Japan) that used an automated edge detection system for the measurement of the brachial artery diameter. A blood pressure cuff was placed around the forearm. The brachial artery was scanned longitudinally $5-10 \mathrm{~cm}$ above the elbow. When the clearest B-mode image of the anterior and posterior intimal interfaces between the lumen and vessel wall was obtained, the transducer was held at the same point throughout the scan by a special probe holder (UNEX Co) to ensure consistency of the image. Depth and gain settings were set to optimise the images of the arterial lumen wall interface. When the tracking gate was placed on the intima, the artery diameter was automatically tracked, and the waveform of diameter changes over the cardiac cycle was displayed in real time using the FMD mode of the tracking system. This allowed the ultrasound images to be optimised at the start of the scan and the transducer position to be adjusted immediately for optimal tracking performance throughout the scan. Pulsed Doppler flow was assessed at baseline and during peak hyperaemic flow, which was confirmed to occur within $15 \mathrm{~s}$ after cuff deflation. Blood flow velocity was calculated from the Doppler data and was displayed as a waveform in real time. The baseline longitudinal image of the artery was acquired for $30 \mathrm{~s}$, and then the blood pressure cuff was inflated to $50 \mathrm{~mm} \mathrm{Hg}$ above systolic pressure for $5 \mathrm{~min}$. The longitudinal image of the artery was recorded continuously until 5 min after cuff deflation. Pulsed Doppler velocity signals were obtained for $20 \mathrm{~s}$ at baseline and for $10 \mathrm{~s}$ immediately after cuff deflation. Changes in brachial artery diameter were immediately expressed as the percentage change relative to the vessel diameter before cuff inflation. FMD was automatically calculated as the percentage change in peak vessel diameter from the baseline value. Percentage of FMD (peak diameter -baseline diameter/baseline diameter) was used for analysis. Blood flow volume was calculated by multiplying the Doppler flow velocity (corrected for the angle) by the heart rate and vessel cross-sectional area $\left(-r^{2}\right)$. Reactive hyperaemia was calculated as the maximum percentage increase in flow after cuff deflation compared with baseline flow.

\section{Statistical analysis}

Results are presented as mean $\pm \mathrm{SD}$. All reported probability values were two-sided, and a probability value of $<0.05$ was considered to be statistically significant. Categorical variables were compared by means of a $\chi^{2}$ test. Comparisons between the groups categorised according to the serum uric acid level were carried out using $\mathrm{P}$ for trend analysis with Bonferroni's test for post hoc comparisons. Relations between variables were determined by Spearman's correlation coefficients analysis. Stepwise multivariate logistic regression analyses were performed to identify factors associated with endothelial dysfunction among potential confounders $(\mathrm{p}<0.20)$ in univariate analysis. Using variables associated with endothelial dysfunction in stepwise multiple regression analyses, we performed the final logistic regression analyses for which results are presented in the results section. The data were processed using the software package Stata V.9 (Stata Co, College Station, Texas, USA).

\section{RESULTS}

\section{Baseline clinical characteristics}

The baseline clinical characteristics are summarised in table 1. Of the 749 participants, $112(15.0 \%)$ had hypertension, $262(35.0 \%)$ had dyslipidemia, $34(4.5 \%)$ had diabetes mellitus, $59(7.9 \%)$ were current smokers, 65 (8.7\%) had metabolic syndrome and $56(8.4 \%)$ had chronic kidney disease. The mean Framingham risk score was $3.94 \pm 3.62 \%$. The mean value of the serum uric acid level was $4.44 \pm 1.09 \mathrm{mg} / \mathrm{dL}$ (median $4.30 \mathrm{mg} / \mathrm{dL}$; IQR $3.80-5.00 \mathrm{mg} / \mathrm{dL}$; range $0.80-10.0 \mathrm{mg} / \mathrm{dL})$. The mean value of FMD was $6.59 \pm 3.60 \%$ (range -4.70 to

\begin{tabular}{|c|c|}
\hline Variables & $\begin{array}{l}\text { Total } \\
(n=749)\end{array}$ \\
\hline Age (years) & $50.2 \pm 10.6$ \\
\hline Body mass index $\left(\mathrm{kg} / \mathrm{m}^{2}\right)$ & $22.0 \pm 3.4$ \\
\hline Systolic blood pressure (mm Hg) & $121.1 \pm 19.0$ \\
\hline Diastolic blood pressure (mm Hg) & $73.9 \pm 12.4$ \\
\hline Heart rate (bpm) & $64.4 \pm 10.2$ \\
\hline Total cholesterol (mmol/L) & $5.37 \pm 0.88$ \\
\hline Triglycerides (mmol/L) & $1.07 \pm 0.71$ \\
\hline HDL-cholesterol (mmol/L) & $1.80 \pm 0.42$ \\
\hline LDL-cholesterol (mmol/L) & $3.11 \pm 0.77$ \\
\hline Glucose (mmol/L) & $5.32 \pm 1.47$ \\
\hline Uric acid (mg/dL) & $4.44 \pm 1.09$ \\
\hline eGFR $\left(\mathrm{mL} / \mathrm{min} / 1.73 \mathrm{~m}^{2}\right)$ & $77.1 \pm 13.3$ \\
\hline Framingham risk score (\%) & $3.94 \pm 3.62$ \\
\hline Hypertension (n (\%)) & $112(15.0)$ \\
\hline Dyslipidemia (n (\%)) & $262(35.0)$ \\
\hline Diabetes mellitus (n (\%)) & $34(4.5)$ \\
\hline Smoking (n (\%)) & 59 (7.9) \\
\hline Metabolic syndrome (n (\%)) & $65(8.7)$ \\
\hline Chronic kidney disease (n (\%)) & $56(8.4)$ \\
\hline Menopause (n (\%)) & $381(50.9)$ \\
\hline Flow-mediated vasodilation (\%) & $6.59 \pm 3.60$ \\
\hline Baseline brachial artery diameter (mm) & $3.40 \pm 0.47$ \\
\hline
\end{tabular}


20.1\%). The division point for the lowest tertile and the middle tertile of FMD was $4.90 \%$. Therefore, endothelial dysfunction was defined as FMD $\leq 4.90 \%$.

\section{Relationships between the serum uric acid level and cardiovascular risk factors}

Univariate regression analysis revealed that the serum uric acid level correlated significantly with age $(r=0.21$, $\mathrm{p}<0.001)$, body mass index $(\mathrm{r}=0.26, \mathrm{p}<0.001)$, systolic blood pressure $(\mathrm{r}=0.17, \mathrm{p}<0.001)$, diastolic blood pressure $(\mathrm{r}=0.17, \mathrm{p}<0.001)$, total cholesterol $(\mathrm{r}=0.23, \mathrm{p}<0.001)$, triglycerides $(\mathrm{r}=0.25, \mathrm{p}<0.001)$, high-density lipoprotein cholesterol $(\mathrm{r}=-0.13, \mathrm{p}=0.002)$, low-density lipoprotein cholesterol $(\mathrm{r}=0.22, \mathrm{p}<0.001)$, glucose $(\mathrm{r}=0.12, \mathrm{p}=0.004)$ and eGFR $(\mathrm{r}=-0.27, \mathrm{p}<0.001)$. Participants were categorised according to the serum uric acid levels (table 2). Age, body mass index, systolic blood pressure, total cholesterol, triglycerides, glucose and Framingham risk score were significantly increased and eGFR was significantly decreased with an increase in the serum uric acid level. As for the prevalence of cardiovascular risk factors, there were significant increases in the prevalence of hypertension, dyslipidemia, current smoking, metabolic syndrome, chronic kidney disease and menopause in relation to an increase in the serum uric acid level.

Relationships between the serum uric acid level and FMD Participants were categorised into four groups on the basis of the serum uric acid level. FMD was significantly decreased with an increase in the serum uric acid level ( $<4 \mathrm{mg} / \mathrm{dL}, 6.85 \pm 3.65 \% ; 4$ to $<5 \mathrm{mg} / \mathrm{dL}, 6.79 \pm 3.60 \%$; 5 to $<6 \mathrm{mg} / \mathrm{dL}, 6.24 \pm 3.58 \%$; $\geq 6 \mathrm{mg} / \mathrm{dL}, 5.27 \pm 3.18 \%$; $\mathrm{P}$ for trend $=0.01$, figure 1 ). Multiple logistic regression analysis revealed that the serum uric acid level was significantly associated with endothelial dysfunction after adjustment for age (OR 1.20; 95\% (CI 1.03 to 1.39; table 3). However, after adjustment for other risk factors, including high-density lipoprotein cholesterol, glucose and smoking status, the significant association between the serum uric acid level and endothelial dysfunction disappeared (OR 1.13; 95\% CI 0.97 to 1.32 ).

\section{Difference in the relationship between the serum uric acid level and endothelial dysfunction according to menopausal status}

Participants were divided into two groups according to menopausal status to investigate the influence of

Table 2 Clinical characteristics according to the serum uric acid levels ${ }^{*} \dagger \S$

\begin{tabular}{|c|c|c|c|c|c|}
\hline \multirow[b]{2}{*}{ Variables } & \multicolumn{4}{|c|}{ Uric acid categories (mg/dL) } & \multirow[b]{2}{*}{ p Value } \\
\hline & $\begin{array}{l}<4.0 \\
(n=245)\end{array}$ & $\begin{array}{l}4.0 \text { to }<5.0 \\
(n=302)\end{array}$ & $\begin{array}{l}5.0 \text { to }<6.0 \\
(n=144)\end{array}$ & $\begin{array}{l}6.0 \leq \\
(n=58)\end{array}$ & \\
\hline Uric acid (mg/dL) & $3.38 \pm 0.54$ & $4.42 \pm 0.28$ & $5.33 \pm 0.26$ & $6.90 \pm 0.90$ & \\
\hline Age (years) & $48.3 \pm 10.9$ & $49.4 \pm 10.1$ & $53.5 \pm 9.9^{*} \dagger$ & $54.7 \pm 10.0^{*} \dagger$ & $<0.001$ \\
\hline Body mass index $\left(\mathrm{kg} / \mathrm{m}^{2}\right)$ & $20.8 \pm 2.8$ & $22.0 \pm 3.4^{*}$ & $23.0 \pm 3.3^{*} \dagger$ & $24.2 \pm 3.9^{*} \dagger$ & $<0.001$ \\
\hline Systolic blood pressure $(\mathrm{mm} \mathrm{Hg})$ & $117.2 \pm 17.6$ & $120.4 \pm 18.3$ & $125.9 \pm 20.4^{*} \dagger$ & $129.2 \pm 20.5^{*} \dagger$ & $<0.001$ \\
\hline Diastolic blood pressure $(\mathrm{mm} \mathrm{Hg})$ & $71.5 \pm 11.4$ & $73.6 \pm 12.1$ & $77.4 \pm 13.4^{*} \dagger$ & $77.0 \pm 12.5^{\star}$ & $<0.001$ \\
\hline Heart rate $(\mathrm{bpm})$ & $64.6 \pm 9.6$ & $63.5 \pm 0.6$ & $65.5 \pm 12.4$ & $65.8 \pm 11.1$ & 0.14 \\
\hline Total cholesterol (mmol/L) & $5.20 \pm 0.82$ & $5.33 \pm 0.86$ & $5.60 \pm 0.91^{*} \dagger$ & $5.67 \pm 0.88^{*} \dagger$ & $<0.001$ \\
\hline Triglycerides (mol/L) & $0.89 \pm 0.51$ & $0.97 \pm 0.50$ & $1.32 \pm 0.81^{*} \dagger$ & $1.69 \pm 1.32^{*}+\S$ & $<0.001$ \\
\hline HDL-cholesterol, (mmol/L) & $1.83 \pm 0.38$ & $1.83 \pm 0.41$ & $1.69 \pm 0.45^{*} \dagger$ & $1.69 \pm 0.54$ & 0.001 \\
\hline LDL-cholesterol (mmol/L) & $3.00 \pm 0.70$ & $3.10 \pm 0.77$ & $3.31 \pm 0.80^{*}$ & $3.19 \pm 0.96$ & 0.006 \\
\hline Glucose (mmol/L) & $5.09 \pm 0.84$ & $5.28 \pm 1.38$ & $5.52 \pm 2.00^{\star}$ & $6.03 \pm 2.09^{*} \dagger$ & $<0.001$ \\
\hline eGFR $\left(\mathrm{mL} / \mathrm{min} / 1.73 \mathrm{~m}^{2}\right)$ & $80.9 \pm 13.7$ & $76.8 \pm 12.1^{\star}$ & $74.4 \pm 13.0^{*}$ & $67.7 \pm 13.8^{*}+\S$ & $<0.001$ \\
\hline Flow-mediated vasodilation (\%) & $6.85 \pm 3.65$ & $6.79 \pm 3.60$ & $6.24 \pm 3.58$ & $5.27 \pm 3.18^{*} \dagger$ & 0.01 \\
\hline Baseline brachial artery diameter (mm) & $3.35 \pm 0.46$ & $3.40 \pm 0.48$ & $3.43 \pm 0.46$ & $3.61 \pm 0.51^{*} \dagger$ & 0.002 \\
\hline Framingham risk score (\%) & $3.27 \pm 3.44$ & $3.49 \pm 2.98$ & $5.08 \pm 3.65^{\star} \dagger$ & $6.33 \pm 5.42^{*} \dagger$ & $<0.001$ \\
\hline Hypertension (n (\%)) & $25(10.2)$ & $34(11.3)$ & $34(23.6)^{*} \dagger$ & $19(32.8)^{*} \dagger$ & $<0.001$ \\
\hline Dyslipidemia (n (\%)) & $59(24.1)$ & $90(29.8)$ & $72(50.0)^{*} \dagger$ & $41(70.7)^{\star}+\S$ & $<0.001$ \\
\hline Diabetes mellitus ( $\mathrm{n}(\%)$ ) & $9(3.7)$ & $8(2.7)$ & $9(6.3)$ & $8(13.8)^{*} \dagger$ & 0.008 \\
\hline Smoking (n (\%)) & $12(4.9)$ & $23(7.6)$ & $15(10.4)$ & $9(15.5)$ & 0.04 \\
\hline Metabolic syndrome (n (\%)) & $12(4.9)$ & $18(6.0)$ & $19(13.2)^{\star}$ & $16(28.1)^{\star} \dagger$ & $<0.001$ \\
\hline Chronic kidney disease (n (\%)) & $10(4.6)$ & $22(7.9)$ & $14(10.9)$ & $10(24.4)^{\star} \dagger$ & 0.001 \\
\hline Menopause (n (\%)) & $103(42.0)$ & $146(48.3)$ & $91(63.2)^{\star} \dagger$ & $41(70.7)^{\star} \dagger$ & $<0.001$ \\
\hline Endothelial dysfunction (n (\%)) & $75(30.6)$ & $87(28.8)$ & $50(34.7)$ & $32(55.2)^{\star}+\S$ & 0.002 \\
\hline
\end{tabular}




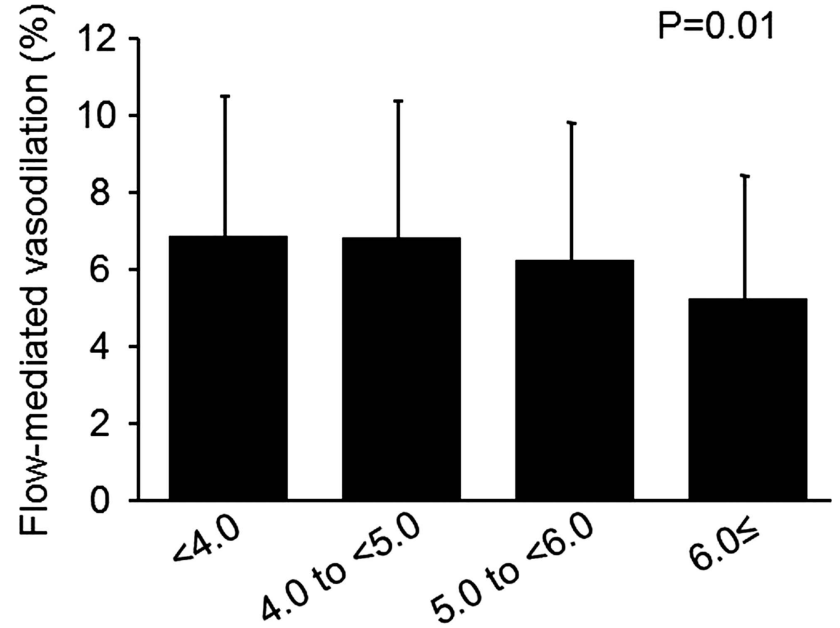

Uric acid categories $(\mathrm{mg} / \mathrm{dL})$

Figure 1 Bar graphs showing flow-mediated vasodilation in women categorised according to the serum uric acid level.

menopause on the relationship between the serum uric acid level and endothelial function (see online supplementary table S1). Of the 749 participants, $368(49.1 \%)$ were premenopausal women and $381(50.9 \%)$ were postmenopausal women. Postmenopausal women were significantly older than premenopausal women $(58.6 \pm 6.3$ vs $41.5 \pm 6.1$ years, $\mathrm{p}<0.001)$. The ages ranged from 30 to 54 years in premenopausal women and 31 to 74 years in postmenopausal women. The serum uric acid level was significantly higher in postmenopausal women than in premenopausal women $(4.64 \pm 1.11$ vs $4.24 \pm 1.03 \mathrm{mg} / \mathrm{dL}$, $\mathrm{p}<0.001)$. FMD was significantly impaired in postmenopausal women compared to premenopausal women $(5.51 \pm 3.14$ vs $7.77 \pm 3.71 \%, \mathrm{p}<0.001)$, and the prevalence of endothelial dysfunction was significantly higher in postmenopausal women than in premenopausal women ( $66.4 \%$ vs $34.0 \%, \mathrm{p}<0.001)$. In postmenopausal women, multiple logistic regression analysis revealed that the serum uric acid level was significantly associated with endothelial dysfunction after adjustment for age (OR, $1.26 ; 95 \%$ CI 1.05 to 1.53 ) (table 4 ). The significant association between the serum uric acid level and

Table 3 Multivariate analysis of the relation between endothelial dysfunction and variables

\begin{tabular}{lllc}
\hline Model & Variables & OR $(95 \% \mathrm{Cl})$ & p Value \\
\hline 1 & Uric acid $(\mathrm{mg} / \mathrm{dL})$ & $1.30(1.13$ to 1.50$)$ & $<0.001$ \\
2 & 1+age & $1.20(1.03$ to 1.39$)$ & 0.02 \\
3 & 2+other variables & $1.13(0.97$ to 1.32$)$ & 0.11 \\
\hline
\end{tabular}

Initial factors included in model 3 were body mass index, systolic blood pressure, total cholesterol, triglycerides, high-density lipoprotein cholesterol, low-density lipoprotein cholesterol, glucose, eGFR and smoking. Using stepwise multiple regression analysis, we selected high-density lipoprotein cholesterol, glucose and smoking as independent factors for endothelial dysfunction (other variables). endothelial dysfunction persisted after adjustment for other risk factors (OR 1.23; $95 \%$ CI 1.01 to 1.50). In contrast, there was no significant association between the serum uric acid level and endothelial dysfunction in premenopausal women (OR 1.14; 95\% CI 0.90 to 1.44; table 4). After adjustment for other risk parameters, the association between the uric acid level and endothelial dysfunction remained insignificant (OR 0.98; 95\% CI 0.75 to 1.26$)$.

\section{DISCUSSION}

In the present study, we demonstrated that the uric acid level was significantly associated with cardiovascular parameters and prevalence of cardiovascular risk factors. Although FMD showed a graded decrease according to the serum uric acid level, uric acid was not an independent risk factor for endothelial dysfunction after adjustment for other cardiovascular risk parameters. However, when participants were divided into two groups according to menopausal status, uric acid was a significantly independent risk factor for endothelial dysfunction even after adjustment for other cardiovascular risk parameters in postmenopausal women, but not in premenopausal women. To our knowledge, this is the first report showing a difference in the relationship between uric acid and endothelial dysfunction depending on menopausal status in women.

As a marker of atherosclerotic diseases, it has been demonstrated that the serum uric acid level is associated with cardiovascular risk factors and subclinical atherosclerosis, such as hypertension, ${ }^{11}$ metabolic syndrome, ${ }^{12}$ kidney disease, ${ }^{13}$ coronary artery calcification ${ }^{42}$ and carotid atherosclerosis. ${ }^{43}$ In the present study, we confirmed that the serum uric acid level was significantly associated with age, body mass index, systolic blood pressure, total cholesterol, triglycerides, glucose and eGFR, most of which are components of metabolic syndrome and CKD. Indeed, the prevalence of hypertension, dyslipidemia, metabolic syndrome and CKD was linearly increased in relation to an increase in the serum uric acid level. An association between uric acid and metabolic syndrome has been demonstrated by the fact that the uric acid level is often elevated in participants with metabolic syndrome and that the prevalence of metabolic syndrome increases linearly in relation to the uric acid level. $^{12} 43$ The mechanism behind the association between an increase in the serum uric acid level and metabolic syndrome is thought to be hyperinsulinaemia, mediated by insulin resistance and visceral adiposity, leading to an increase in uric acid absorption in renal tubules. ${ }^{44}$ Uric acid levels are also frequently elevated in patients with kidney disease as a result of reduction in GFR and renal urate excretion. ${ }^{45}$ In addition, several epidemiological studies have shown a link between the elevated serum uric acid level and subsequent cardiovascular events. ${ }^{1-10}$ The association between the serum uric acid level and cardiovascular disease has been reported 
Table 4 Multivariate analysis of the relation between endothelial dysfunction and variables

\begin{tabular}{|c|c|c|c|c|c|}
\hline \multirow[b]{2}{*}{ Model } & \multirow[b]{2}{*}{ Covariates } & \multicolumn{2}{|l|}{ Postmenopausal } & \multicolumn{2}{|l|}{ Premenopausal } \\
\hline & & $\overline{\text { OR }(95 \% \mathrm{Cl})}$ & p Value & OR (95\% Cl) & p Value \\
\hline 1 & Uric acid (mg/dL) & $1.27(1.05$ to 1.53$)$ & 0.01 & $1.14(0.90$ to 1.44$)$ & 0.28 \\
\hline 2 & $1+$ age & $1.26(1.05$ to 1.53$)$ & 0.02 & $1.12(0.85$ to 1.39$)$ & 0.50 \\
\hline 3 & $2+$ other variables & $1.23(1.01$ to 1.50$)$ & 0.04 & $0.98(0.75$ to 1.26$)$ & 0.85 \\
\hline
\end{tabular}

to be generally stronger in women than in men. ${ }^{9} 46-48$ These findings suggest that the uric acid level is a biochemical marker of atherosclerotic disease and a useful predictor of the development of cardiovascular diseases.

Despite the association between the elevated uric acid level and cardiovascular conditions, uric acid has not been established as an independent causal risk factor for cardiovascular disease because of the link between uric acid and established cardiovascular risk factors. Another possible explanation for the difficulty in determining the role of uric acid in cardiovascular disease is that uric acid may function as a powerful antioxidant and as a scavenger of singlet oxygen and radicals. ${ }^{49} 50$ In patients with cardiovascular disease, an increase in the uric acid level might therefore be considered as a compensatory mechanism to counteract the oxidative stress induced in these conditions. Although it remains controversial whether uric acid is a causative factor or merely a marker of cardiovascular disease, some epidemiological studies have demonstrated that the association between uric acid and cardiovascular disease remains significant even after adjustment for concomitant risk factors, suggesting that uric acid per se is an independent risk factor for cardiovascular disease. ${ }^{5}$ 7-10

Although the precise mechanism behind the relationship between uric acid and cardiovascular disease remains to be elucidated, growing evidence indicates that endothelial dysfunction induced by uric acid plays an important role in the development of cardiovascular disease. ${ }^{45}$ Several lines of evidence suggest that uric acid also has proinflammatory effects on endothelial cells, leading to the reduction of endothelial nitric oxide bioavailability and consequent endothelial dysfunction. ${ }^{17} 18$ Yu et $a l^{18}$ demonstrated that uric acid enhances the production of reactive oxygen species by activation of the local renin-angiotensin system, particularly angiotensin II, in human endothelial vascular cells and that probenecid, an inhibitor of urate transporter, inhibits uric acidinduced oxidative stress. Thus, uric acid is thought to mediate endothelial dysfunction by generating oxidative stress once absorbed into endothelial cells. In a clinical setting, the measurement of FMD as an index of endothelium-dependent vasodilation in the brachial artery using high-resolution ultrasound has been widely used as a method for assessing vascular function. ${ }^{20-23}$ Although several investigators have shown that uric acid correlates inversely with FMD and that uric acid is an independent predictor of FMD, the participants in those studies were limited to a small number of participants or highly selected participants, such as patients with increased cardiovascular risk, ${ }^{30}$ hyperuricemia ${ }^{32}$ or nondiabetic CKD. ${ }^{33}$ In addition, uric acid has been shown to be a significantly independent risk factor for endothelial dysfunction in men in an analysis of a large population, ${ }^{34}$ but there is little information on the relationship between uric acid and FMD in women. As a risk marker, we demonstrated that the serum uric acid level was significantly associated with FMD in women. FMD was significantly impaired with an increase in the serum uric acid level. FMD is known to be impaired as a consequence of cumulative cardiovascular risk factors. ${ }^{21} 51$ Therefore, a significant decrease in FMD according to the serum uric acid level may reflect significant associations between uric acid and other cardiovascular risk factors, including hypertension, dyslipidemia, metabolic syndrome and CKD, as a risk marker for cardiovascular disease in women. These findings provide a rationale for the relationships of uric acid with cardiovascular disease and mortality being generally strong in women.

As for the role of uric acid as a causal risk factor in endothelial function, multivariate analysis performed for the entire population indicated that uric acid was not an independent predictor of endothelial dysfunction after adjustment for other risk factors. However, when participants were divided into two groups according to menopausal status, multivariate analyses revealed that uric acid was a significantly independent risk factor for endothelial dysfunction in postmenopausal women but not in premenopausal women. The incidence of cardiovascular diseases in women is lower than that in men until around the age of menopause, after which it increases markedly and becomes equal to that of their male counterparts, suggesting a protective effect of endogenous ovarian hormones on atherosclerosis. ${ }^{52}$ Ovarian hormones, especially oestradiol, have been suggested to have protective effects on endothelial function. ${ }^{53}$ In addition to its protective effect on endothelial function, oestradiol has been shown to lower the uric acid level through mechanisms involving renal clearance, secretion and reabsorption. ${ }^{55-57}$ Therefore, endogenous oestradiol may preserve endothelial function and lower the serum uric acid level regardless of the presence or absence of cardiovascular risk factors, resulting in the weak relationship between uric acid and endothelial dysfunction in premenopausal women. Our findings in the 
analysis of premenopausal women are consistent with the results of a previous study demonstrating that uric acid was not an independent risk factor of FMD in young women aged $30-45$ years. ${ }^{58}$ In contrast to premenopausal women, uric acid remained a significantly independent risk for endothelial dysfunction even after adjustment for other risk factors in postmenopausal women. Although Maxwell et $a l^{29}$ reported that uric acid was not an independent determinant of FMD in women, the non-independent association between FMD and uric acid observed in their study may be, in part, attributed to inclusion of entire women in the analysis for the relationship between FMD and uric acid without taking into account menopausal status. The increased cardiovascular risk in postmenopausal women has been suggested to be associated with impairment of endothelial function after menopause. ${ }^{59}$ There is a possibility that treatment of hyperuricemia in postmenopausal women will improve endothelial function, leading to a decrease in cardiovascular events.

There were some limitations in this study. The crosssectional design did not allow us to establish a definitive causal relationship between hyperuricemia and endothelial dysfunction. In addition, multiple factors, such as vitamins, phosphate and statin use, that are known to influence FMD and residual unrecognised confounding factors were not taken into account in this study. Future prospective and interventional studies are certainly warranted to obtain more specific conclusions as to whether hyperuricemia should be treated, which subgroup should be treated and whether treatment of hyperuricemia improves endothelial function with a subsequent decrease in cardiovascular events.

In conclusion, uric acid is a useful marker for endothelial function in women. Significant relationships between the serum uric acid level and cardiovascular risk factors, including hypertension, dyslipidemia, metabolic syndrome and CKD, may result in a significant association between FMD and the serum uric acid level as a risk marker of atherosclerotic diseases. Uric acid, as a causal cardiovascular risk factor, may be an independent risk for endothelial dysfunction in postmenopausal women but not in premenopausal women. Further studies are needed to investigate whether treatment for hyperuricemia improves endothelial function in postmenopausal women.

\footnotetext{
Author affiliations

${ }^{1}$ Department of Cardiovascular Medicine, Hiroshima University Graduate School of Biomedical Sciences, Hiroshima, Japan

${ }^{2}$ Division of Regeneration and Medicine, Hiroshima University Hospital, Hiroshima, Japan

${ }^{3}$ Department of Gastroenterology and Metabolism, Institute of Biomedical and Health Sciences, Graduate School of Biomedical Sciences, Hiroshima University, Hiroshima, Japan

${ }^{4}$ Hirohsima International University, Hiroshima, Japan

${ }^{5}$ Department of Cardiovascular Regeneration and Medicine, Research Institute for Radiation Biology and Medicine, Hiroshima University, Hiroshima, Japan ${ }^{6}$ The Second Department of Internal Medicine, Tokyo Medical University, Tokyo, Japan
}

${ }^{7}$ Division of Biomedical Engineering, National Defense Medical College Research Institute, Tokorozawa, Japan

Acknowledgements The authors would like to thank Megumi Wakisaka, Miki Kumiji, Kiichiro Kawano and Satoko Michiyama for their excellent secretarial assistance.

Contributors TM and $\mathrm{YH}$ were involved in the drafting of the article and conception of the study. JS, NF, NI, SM, YI, MK, TM, TH, CG, KN, AN, BT and $\mathrm{HT}$ were involved in performing the ultrasonography. KC, YK and AY were involved in revising the manuscript for important intellectual content. All the authors approved the final version of the article to be published.

Funding This study was supported in part by a Grant-in-Aid for Scientific Research from the Ministry of Education, Science and Culture of Japan (1859081500 and 21590898) and a Grant in Aid of Japanese Arteriosclerosis Prevention Fund.

Competing interests None.

Patient consent Obtained.

Provenance and peer review Not commissioned; externally peer reviewed.

Data sharing statement No additional data are available.

Open Access This is an Open Access article distributed in accordance with the Creative Commons Attribution Non Commercial (CC BY-NC 3.0) license, which permits others to distribute, remix, adapt, build upon this work noncommercially, and license their derivative works on different terms, provided the original work is properly cited and the use is non-commercial. See: http:// creativecommons.org/licenses/by-nc/3.0/

\section{REFERENCES}

1. Reunanen $\mathrm{A}$, Takkunen $\mathrm{H}$, Knekt $\mathrm{P}$, et al. Hyperuricemia as a risk factor for cardiovascular mortality. Acta Med Scand Suppl 1982;668:49-59.

2. Levine W, Dyer AR, Shekelle RB, et al. Serum uric acid and 11.5-year mortality of middle-aged women: findings of the Chicago Heart Association Detection Project in Industry. J Clin Epidemiol 1989;42:257-67.

3. Wannamethee SG, Shaper AG, Whincup PH. Serum urate and the risk of major coronary heart disease events. Heart 1997;78:147-53.

4. Lehto S, Niskanen L, Ronnemaa T, et al. Serum uric acid is a strong predictor of stroke in patients with non-insulin-dependent diabetes mellitus. Stroke 1998;29:635-9.

5. Alderman $\mathrm{MH}$, Cohen $\mathrm{H}$, Madhavan $\mathrm{S}$, et al. Serum uric acid and cardiovascular events in successfully treated hypertensive patients. Hypertension 1999;34:144-50.

6. Culleton BF, Larson MG, Kannel WB, et al. Serum uric acid and risk for cardiovascular disease and death: the Framingham Heart Study. Ann Intern Med 1999;131:7-13.

7. Moriarity JT, Folsom AR, Iribarren $\mathrm{C}$, et al. Serum uric acid and risk of coronary heart disease: Atherosclerosis Risk in Communities (ARIC) Study. Ann Epidemiol 2000;10:136-43.

8. Verdecchia P, Schillaci G, Reboldi G, et al. Relation between serum uric acid and risk of cardiovascular disease in essential hypertension. The PIUMA Study. Hypertension 2000;36:1072-8.

9. Fang J, Alderman MH. Serum uric acid and cardiovascular mortality the NHANES I epidemiologic follow-up study, 1971-1992. National Health and Nutrition Examination Survey. JAMA 2000;283:2404-10.

10. Ioachimescu AG, Brennan DM, Hoar BM, et al. Serum uric acid is an independent predictor of all-cause mortality in patients at high risk of cardiovascular disease: a Preventive Cardiology Information System (PreCIS) Database Cohort Study. Arthritis Rheum 2008;58:623-30.

11. Cannon PJ, Stason WB, Demartini FE, et al. Hyperuricemia in primary and renal hypertension. N Engl J Med 1966;275:457-64.

12. Ford ES, Li C, Cook S, et al. Serum concentrations of uric acid and the metabolic syndrome among US children and adolescents. Circulation 2007;115:2526-32.

13. Siu YP, Leung KT, Tong MK, et al. Use of allopurinol in slowing the progression of renal disease through its ability to lower serum uric acid level. Am J Kidney Dis 2006;47:51-9.

14. Feig DI, Kang DH, Johnson RJ. Uric acid and cardiovascular risk. N Engl J Med 2008;359:1811-21.

15. Gagliardi AC, Miname MH, Santos RD. Uric acid: a marker of increased cardiovascular risk. Atherosclerosis 2009;202:11-17. 
16. Khosla UM, Zharikov S, Finch JL, et al. Hyperuricemia induces endothelial dysfunction. Kidney Int 2005;67:1739-42.

17. Kang DH, Park SK, Lee IK, et al. Uric acid-induced C-reactive protein expression: implication on cell proliferation and nitric oxide production of human vascular cells. J Am Soc Nephrol 2005;16:3553-62.

18. Yu MA, Sanchez-Lozada LG, Johnson RJ, et al. Oxidative stress with an activation of the renin-angiotensin system in human vascular endothelial cells as a novel mechanism of uric acid-induced endothelial dysfunction. J Hypertens 2010;28:1234-42.

19. Ross R. Atherosclerosis-an inflammatory disease. N Engl J Med 1999;340:115-26.

20. Celermajer DS, Sorensen KE, Gooch VM, et al. Non-invasive detection of endothelial dysfunction in children and adults at risk of atherosclerosis. Lancet 1992;340:1111-15.

21. Benjamin EJ, Larson MG, Keyes MJ, et al. Clinical correlates and heritability of flow-mediated dilation in the community: the Framingham Heart Study. Circulation 2004;109:613-19.

22. Idei N, Nishioka K, Soga J, et al. Vascular function and circulating progenitor cells in thromboangitis obliterans (Buerger's disease) and atherosclerosis obliterans. Hypertension 2011;57:70-8.

23. Soga J, Noma K, Hata T, et al. Rho-associated kinase activity, endothelial function, and cardiovascular risk factors. Arterioscler Thromb Vasc Biol 2011;31:2353-9.

24. Fujimura N, Noma K, Hata T, et al. Mineralocorticoid receptor blocker eplerenone improves endothelial function and inhibits Rho-associated kinase activity in patients with hypertension. Clin Pharmacol Ther 2012;91:289-97.

25. Modena MG, Bonetti L, Coppi F, et al. Prognostic role of reversible endothelial dysfunction in hypertensive postmenopausal women. J Am Coll Cardiol 2002;40:505-10.

26. Gokce N, Keaney JF Jr, Hunter LM, et al. Risk stratification for postoperative cardiovascular events via noninvasive assessment of endothelial function: a prospective study. Circulation 2002;105:1567-72.

27. Brevetti G, Silvestro A, Schiano V, et al. Endothelial dysfunction and cardiovascular risk prediction in peripheral arterial disease: additive value of flow-mediated dilation to ankle-brachial pressure index. Circulation 2003;108:2093-8.

28. Lerman A, Zeiher AM. Endothelial function: cardiac events. Circulation 2005;111:363-8.

29. Maxwell AJ, Bruinsma KA. Uric acid is closely linked to vascular nitric oxide activity. Evidence for mechanism of association with cardiovascular disease. J Am Coll Cardiol 2001;38:1850-8.

30. Mercuro G, Vitale C, Cerquetani E, et al. Effect of hyperuricemia upon endothelial function in patients at increased cardiovascular risk. Am J Cardiol 2004;94:932-5.

31. Kato M, Hisatome I, Tomikura Y, et al. Status of endothelial dependent vasodilation in patients with hyperuricemia. $A m \mathrm{~J}$ Cardiol 2005;96:1576-8.

32. Ho WJ, Tsai WP, Yu KH, et al. Association between endothelial dysfunction and hyperuricaemia. Rheumatology (Oxford) 2010;49:1929-34

33. Kanbay M, Yilmaz MI, Sonmez A, et al. Serum uric acid level and endothelial dysfunction in patients with nondiabetic chronic kidney disease. Am J Nephrol 2011;33:298-304.

34. Tomiyama $\mathrm{H}$, Higashi $\mathrm{Y}$, Takase $\mathrm{B}$, et al. Relationships among hyperuricemia, metabolic syndrome, and endothelial function. Am J Hypertens 2011;24:770-4.

35. Chobanian AV, Bakris GL, Black HR, et al. The Seventh Report of the Joint National Committee on Prevention, Detection, Evaluation, and Treatment of High Blood Pressure: the JNC 7 report. JAMA 2003;289:2560-72.

36. American Diabetes Association: clinical practice recommendations 1999. Diabetes Care 1999;22(Suppl 1):S1-114.

37. Expert panel on Detection, Evaluation, and Treatment of High Blood Cholesterol in Adults. Executive Summary of The Third Report of The National Cholesterol Education Program (NCEP) Expert Panel on Detection, Evaluation, and Treatment of High Blood Cholesterol in Adults (Adult Treatment Panel III). JAMA 2001;285:2486-97.

38. Wilson PW, Castelli WP, Kannel WB. Coronary risk prediction in adults (the Framingham Heart Study). Am J Cardiol 1987:59:91G-4G.
39. Matsuo S, Imai E, Horio M, et al. Revised equations for estimated GFR from serum creatinine in Japan. Am J Kidney Dis 2009;53:982-92.

40. National Kidney Foundation. K/DOQI clinical practice guidelines for chronic kidney disease: evaluation, classification, and stratification. Am J Kidney Dis 2002;39(2 Suppl 1):S1-266.

41. McKinlay SM. The normal menopause transition: an overview. Maturitas 1996;23:137-45.

42. Coutinho Tde A, Turner ST, Peyser PA, et al. Associations of serum uric acid with markers of inflammation, metabolic syndrome, and subclinical coronary atherosclerosis. Am J Hypertens 2007;20:83-9.

43. Ishizaka N, Ishizaka $\mathrm{Y}$, Toda $\mathrm{E}$, et al. Association between serum uric acid, metabolic syndrome, and carotid atherosclerosis in Japanese individuals. Arterioscler Thromb Vasc Biol 2005;25:1038-44.

44. Quinones Galvan A, Natali A, Baldi S, et al. Effect of insulin on uric acid excretion in humans. Am J Physiol 1995;268(1 Pt 1):E1-5.

45. Johnson RJ, Kang DH, Feig D, et al. Is there a pathogenetic role for uric acid in hypertension and cardiovascular and renal disease? Hypertension 2003;41:1183-90.

46. Bengtsson C, Lapidus L, Stendahl C, et al. Hyperuricaemia and risk of cardiovascular disease and overall death. A 12-year follow-up of participants in the population study of women in Gothenburg, Sweden. Acta Med Scand 1988;224:549-55.

47. Freedman DS, Williamson DF, Gunter EW, et al. Relation of serum uric acid to mortality and ischemic heart disease. The NHANES I Epidemiologic Follow-up Study. Am J Epidemiol 1995;141:637-44.

48. Tuttle KR, Short RA, Johnson RJ. Sex differences in uric acid and risk factors for coronary artery disease. Am J Cardiol 2001;87:1411-14

49. Ames BN, Cathcart R, Schwiers E, et al. Uric acid provides an antioxidant defense in humans against oxidant- and radical-caused aging and cancer: a hypothesis. Proc Natl Acad Sci USA 1981;78:6858-62.

50. Nieto FJ, Iribarren C, Gross MD, et al. Uric acid and serum antioxidant capacity: a reaction to atherosclerosis? Atherosclerosis 2000;148:131-9.

51. Celermajer DS, Sorensen KE, Bull C, et al. Endothelium-dependent dilation in the systemic arteries of asymptomatic subjects relates to coronary risk factors and their interaction. J Am Coll Cardiol 1994;24:1468-74.

52. Lerner DJ, Kannel WB. Patterns of coronary heart disease morbidity and mortality in the sexes: a 26-year follow-up of the Framingham population. Am Heart J 1986;111:383-90.

53. Lieberman $\mathrm{EH}$, Gerhard MD, Uehata A, et al. Estrogen improves endothelium-dependent, flow-mediated vasodilation in postmenopausal women. Ann Intern Med 1994;121:936-41.

54. Hashimoto $\mathrm{M}$, Akishita $\mathrm{M}$, Eto $\mathrm{M}$, et al. Modulation of endothelium-dependent flow-mediated dilatation of the brachial artery by sex and menstrual cycle. Circulation 1995;92:3431-5.

55. Nicholls A, Snaith ML, Scott JT. Effect of oestrogen therapy on plasma and urinary levels of uric acid. Br Med J 1973;1: 449-51.

56. Hak AE, Choi HK. Menopause, postmenopausal hormone use and serum uric acid levels in US women - the Third National Health and Nutrition Examination Survey. Arthritis Res Ther 2008;10:R116.

57. Mumford SL, Dasharathy SS, Pollack AZ, et al. Serum uric acid in relation to endogenous reproductive hormones during the menstrual cycle: findings from the BioCycle Study. Hum Reprod 2013;28:1853-62.

58. Oikonen M, Wendelin-Saarenhovi M, Lyytikainen LP, et al. Associations between serum uric acid and markers of subclinical atherosclerosis in young adults. The cardiovascular risk in Young Finns study. Atherosclerosis 2012;223:497-503.

59. Celermajer DS, Sorensen KE, Spiegelhalter DJ, et al. Aging is associated with endothelial dysfunction in healthy men years before the age-related decline in women. J Am Coll Cardiol 1994;24:471-6.

60. Taddei S, Virdis A, Ghiadoni L, et al. Menopause is associated with endothelial dysfunction in women. Hypertension 1996;28: 576-82. 